\title{
The acute hepatic porphyrias
}

\author{
Bruce Wang \\ Department of Medicine, University of California San Francisco, San Francisco, CA, USA \\ Correspondence to: Bruce Wang. Department of Medicine, University of California San Francisco, San Francisco, CA, USA. Email: bruce.wang@ucsf.edu.
}

\begin{abstract}
The acute hepatic porphyrias (AHP) are a group of four inherited diseases of heme biosynthesis. They present with similar severe, episodic, acute neurovisceral symptoms due to abnormally elevated levels of porphyrin precursors delta-aminolevulinic acid (ALA). Recently genetic screening indicates that the prevalence of mutation carrier state is more common than previously thought, occurring in 1 in 1,500 , though the clinical penetrance of symptomatic AHP is low at $\sim 1 \%$. Symptomatic attacks occur primarily in females during their reproductive years. In an acute porphyria attack, the primary symptom is abdominal pain, due to intestinal dysmotility from autonomic nerve injury. Other manifestations include seizures, weakness and mood changes, point to injury involving peripheral and central nervous system. Due to the non-specific nature of the symptoms and signs in AHP, the diagnosis is often delayed by many years. The diagnosis of AHP depends on biochemical evidence of elevated ALA and PBG levels in urine during symptomatic attacks. Genetic testing is used for confirmation of the gene involved and the exact mutation. Treatment involves administration of heme, which downregulates production of ALA. Long-term management centers on educating genetic carriers on avoiding triggers that increase the risk of acute attacks and screening family members.
\end{abstract}

Keywords: Porphyria; genetic disease; heme; neurovisceral attacks; rare diseases

Received: 28 October 2019; Accepted: 18 December 2019; Published: 05 April 2021.

doi: $10.21037 /$ tgh-2020-01

View this article at: http://dx.doi.org/10.21037/tgh-2020-01

\section{Heme and porphyrias}

Porphyrias are inherited disorders of heme biosynthesis. Heme is an essential molecule that carries out a wide array of functions necessary for aerobic life. It is the prosthetic group for essential molecules including hemoglobin, mitochondrial cytochromes and cytochrome P-450s. Heme is synthesized through eight enzymatic steps, and mutations that lead to defective activity in heme synthesis enzymes result in the eight inherited porphyrias. As a result, there is abnormal accumulation of the intermediates that precede the enzyme deficiency. Symptoms for the porphyrias are due to the specific intermediates that accumulate.

The acute hepatic porphyrias, acute intermittent porphyria (AIP), variegate porphyria (VP), hereditary coproporphyria (HCP) and 5-aminolevulinic acid dehydratase deficiency porphyria (ALAD) all present with similar episodic acute neurovisceral attacks due to abnormal accumulation of the neurotoxic porphyrin precursors delta- aminolevulinic acid (ALA) and porphobilinogen (PBG).

The process of heme synthesis is shown in Figure 1. The conversion of glycine and succinyl coenzyme A to ALA by the mitochondrial enzyme ALA synthase (ALAS) is the first and rate limiting step in heme synthesis. In subsequent reactions, two molecules of ALA combine to form the porphyrin precursor PBG. Four PBGs are linked and cyclized to form the first porphyrin of the pathway, uroporphyrinogen I. Subsequent reactions in the pathway produce porphyrin intermediates of progressively decreasing water solubility until the formation of heme (Figure 1). It's important to note that the first two intermediates, ALA and PBG are porphyrin precursors, not porphyrins. The excretion of the hydrophilic ALA, PBG, and uroporphyrin are entirely in urine, whereas coproporphyrin is in both urine and feces, and protoporphyrin only in feces.

Though all cells in the human body synthesize heme, it is predominantly formed by erythroblasts in the bone 


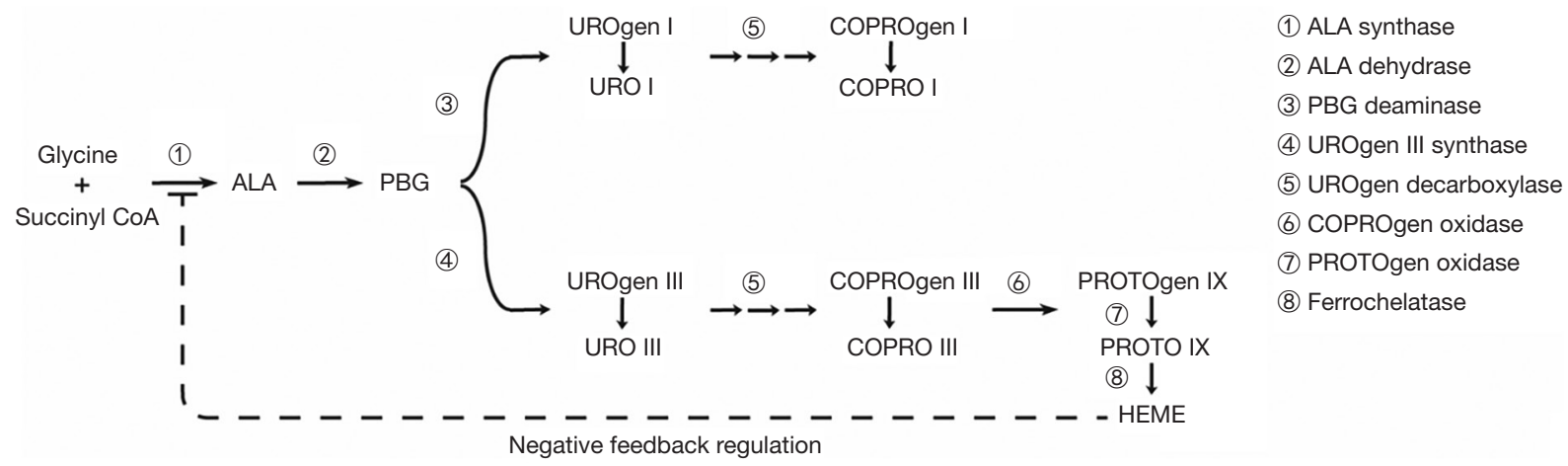

Figure 1 The pathway of heme synthesis. Between the two arms of the pathway, depicting the isomer I and isomer III porphyrin, is a box indicating the number of carboxyl substituents for each porphyrin. ALA, $\delta$-aminolevulinic acid; PBG, porphobilinogen; URO, uroporphyrin; COPRO, coproporphyrin; PROTO, protoporphyrin.

marrow (75\% to $80 \%)$ and hepatocytes in the liver $(15 \%$ to $20 \%$ ). The regulation of heme synthesis differs in bone marrow compared to other tissues. The rate-limiting step for the pathway as a whole is formation of ALA by ALAS. Two forms of ALAS are present. In non-erythroid cells, including hepatocytes, the house-keeping gene ALAS1 is expressed. ALAS1 is subject to feedback regulation by heme to ensure that production of ALA is appropriate to the demand for heme. ALAS2 is the form found in bone marrow and serves heme synthesis in erythroblasts for the production of hemoglobin. ALAS2 is regulated by iron, rather than heme.

\section{Patbophysiology of acute bepatic porphyrias}

Porphyrin precursors, in particular ALA, are likely neurotoxins (see below), whereas porphyrins are light absorbing chemicals that act as photosensitizers, resulting in skin damage. In VP and HCP, both porphyrin precursors and porphyrins accumulate, and patients with these types can present with both neurovisceral attacks and cutaneous symptoms.

In AHP, the severity of the overproduction of intermediates is dependent on the demand for heme. When the need for heme production is low, ALAS1 typically remains the rate-limiting step in the pathway even with the presence of a partially defective enzyme downstream, and there is minimal accumulation of heme intermediates. Under inducing conditions that increase demand for heme synthesis, ALAS1 expression increases, and the defective enzymatic step becomes the rate-limiting step. With persistence of the demand for heme, ALAS1 expression remains elevated, resulting in abnormal accumulation of ALA and PBG. In HCP and VP, the accumulation of coproporphyrinogen III and protoporphyrinogen IX, respectively, inhibits the function of hepatic hydroxymethylbilane synthase (HMBS, also known as PBG deaminase) (1). This is the metabolic setting for an acute attack of AHP.

While several hypotheses have been proposed regarding the pathogenesis of episodic acute attacks in AHP patients, including relative heme deficiency in nerve tissue, recent data has pointed to excess circulating ALA as the etiology.

Several lines of evidence point to excess hepatic ALA production as mediator of neurotoxicity in acute attacks. First, acute attacks are always accompanied by elevated plasma or urine ALA. Second, symptom relief after effective therapy correlates with decreased ALA levels (2). Third, in lead intoxication and hereditary tyrosinemia, two nonporphyria conditions with identical symptoms to those of AHP, ALA (but not PBG) is elevated. In addition, a clinical trial using recombinant HMBS enzyme caused a rapid reduction in plasma $\mathrm{PBG}$ without affecting ALA levels and had no effect on symptoms in AIP patients (3). Fourth, liver transplantation, which has no effect on heme synthesis deficiency in neurologic tissue, is curative for AHPs (4). Lastly, domino liver transplantation of AIP livers was sufficient to cause acute attacks in recipients who have otherwise normal heme synthesis in neurologic tissue (5).

Two mechanisms of ALA induced neurotoxicity have been postulated. The first is that ALA acts as a gammaaminobutyric acid (GABA) agonist. GABA is the main 
Table 1 Symptoms and signs in acute hepatic porphyria at presentation

\begin{tabular}{lc}
\hline Symptom/signs & Frequency (\%) \\
\hline Abdominal pain & 74 \\
Nausea, vomiting & 73 \\
Weakness & 63 \\
Constipation & 60 \\
Anxiety/Depression & 55 \\
Palpitations & 50 \\
Hypertension & 40 \\
Diarrhea & 29 \\
Sun sensitivity & 20 \\
Seizures & 9 \\
\hline
\end{tabular}

Data taken from Bonkovsky (37). The findings in hereditary coproporphyria and variegate porphyria are similar (36).

inhibitory neurotransmitter in the central nervous system, and GABA receptors are present in the myenteric plexus of the intestines to regulate peristalsis and muscle tone. In vitro studies support ALA signaling through GABA receptors, which could lead to ileus like symptoms seen in acute attacks $(6,7)$. Furthermore, In vivo studies show that ALA may induce GABA-mediated inhibition of melatonin release from the pineal gland (8).

ALA may also act as a direct neurotoxin. In the presence of iron, ALA undergoes oxidation to release oxygen radicals $(9,10)$, that can be directly damaging to nerves (11-15). In vitro studies show that ALA induces neuron misfiring (16), neuronal cell death (17), and diminished contraction and muscle tone of isolated intestines (18). Injection of ALA in vivo into rat ventricles can induce seizures (19). In people, ALA administration has resulted in severe polyneuropathy resembling symptoms of an acute attack (20).

\section{Genetics}

AIP, HCP and VP are autosomal dominant disorders with low penetrance. ALAD porphyria is a very rare autosomal recessive disorder with only 5 reported cases in the world literature (21-24). Disease-causing mutations in AHP genes typically result in at least $50 \%$ reduction of the activity in the corresponding enzyme. While all AHPs are rare diseases, recent population level genetic studies have shown that the prevalence of genetic carrier state for AHPs is much higher than previously thought. Initial clues came from a screen of healthy blood donors in France, where the prevalence of disease-causing genetic mutations for acute intermittent porphyria (AIP) was 1:1,650 (25). Two recent large screens of genomic databases have reached a similar mutation prevalence of $1: 1,300$ to $1: 1,785(26,27)$.

The vast majority of genetic carriers of AHP do not experience symptomatic acute attacks in their lifetime. Recent data from Europe estimate the incidence of symptomatic AHP at $\sim 0.5$ per 100,000 (28). Based on this, the estimated penetrance of symptomatic disease is $~ 1 \%$ of AIP gene carriers (27) with HCP and VP thought to be more often latent than AIP (29). The low penetrance indicates the likely presence of additional factors that are required for symptomatic manifestation of AHPs.

AHPs are present worldwide, though a few areas have higher prevalence. The prevalence of AIP in northern Scandinavia is unusually high due to a founder effect and geographic isolation. In South Africa, the prevalence of VP from the a single genotype is high in people of Dutch ancestry (Afrikaners) due to a founder effect from one of the original Dutch settlers in the late 17th century (30).

Rare cases of homozygous AIP have been reported, which results in severely depressed HBMS activity to $\sim 2-5 \%$ of normal. These cases typically present in early childhood with severe neurologic and developmental defects with rapid progression of symptoms are early death $(31,32)$. In South Africa, homozygosity for the founder mutation is seen and associated with severe disease starting in childhood (33). Compound heterozygous VP has also been reported in a child with developmental and language delay (34). Harderoporphyria is a variant of HCP and is also an autosomal recessive disorder. Its manifestations are markedly elevated urinary porphyrins and photosensitivity, without acute neurovisceral attacks (35).

\section{Clinical manifestations}

\section{Acute attacks}

All four AHPs present with identical clinical symptoms of episodic, severe neurovisceral attacks (36). Approximately $90 \%$ of symptomatic patients are female, and attacks typically begin only after the onset of menses and are rare after menopause. The most common symptoms are listed in Table 1. In an acute attack, patients present with severe non-focal abdominal pain that is aching more often than colicky. Nausea, vomiting and constipation are typically 
present. The symptoms buildup over the course of several days rather than hours. The physical exam is usually normal without abdominal guarding or rebound tenderness. Laboratory tests may show hyponatremia, which can be seen in up to $30 \%$ of acute attacks, but are otherwise unremarkable [ref]. Abdominal imaging is normal except for signs of ileus.

Neurologic symptoms are present in up to $70 \%$ of acute attacks (36). The peripheral, autonomic and central nervous system can all be affected. The most common symptom is weakness which starts proximally and progresses distally. Sensory disturbances such as paresthesias and numbness occur in about half of the patients (38). The rate of symptom progression is variable but can be rapid, progressing to flaccid tetraplegia and respiratory paralysis within days. Autonomic involvement including tachycardia and hypertension are common. Central nervous system involvement includes mental status changes ranging from depression to delusions are seen in $50-75 \%$ of acute attacks $(36,39)$. Seizures are seen in up to $20 \%$ of acute attacks $(36)$.

\section{Recurrent acute attacks}

The vast majority, at least $90 \%$, of symptomatic AHP patients experience only one or a few acute attacks in their lifetime. However, a small percentage of symptomatic AHP patients experience frequent recurrent attacks. These patients are also usually women, some with attacks during the luteal phase of their menstrual cycles. In addition to the acute attack symptoms described above, more than $50 \%$ of patients with frequent, recurrent attacks report chronic daily neurologic symptoms, and 35\% had a diagnosis of neuropathy, outside of overt attack episodes (40,41). These patients typically have persistently elevated levels of ALA and PBG (42). It is unclear whether their chronic symptoms are due to unrecovered neurologic damage from frequent severe acute attacks or persistently elevated ALA.

\section{Asymptomatic bigh excretors}

Some individuals who carry an AHP mutation have persistently elevated ALA and PBG but have never experienced acute attack symptoms. This group of asymptomatic high excretors (ASHE) may be at increased risk, relative to mutation carriers with normal ALA, for an acute attack or for chronic renal or hepatic injury $(3,43)$. Emerging data has also shown that these patients may have chronic, subacute neurologic symptoms (44). Further study is needed to determine whether this is due to chronically high circulating levels of ALA.

\section{Diagnosis}

Diagnosis of symptomatic AHP requires biochemical testing. The hallmark of all acute attacks is elevated ALA in the urine or plasma. In all AHP except ALAD porphyria, PBG is also elevated. During acute attacks, both ALA and PBG are at elevated at least 5-fold the upper limit of normal. The levels are high enough that a random urine sample is sufficient, and plasma or 24-hour urine collection is not needed. It is important to note that since ALA and PBG are porphyrin precursors they are not included in tests of porphyrins, which typically measures fractionate porphyrins.

Both ALA and PBG can be measured with high sensitivity and specificity (45-47). Unfortunately, these tests are performed only at large reference laboratories and results take 1-2 weeks. Rapid, qualitative urine PBG tests have been available since the 1950s (Watson-Schwartz test) (48), but their clinical use has been limited because current regulations limit its use certified laboratory technicians. No other rapid tests for ALA or PBG are currently available to most healthcare center.

For the majority of AHP patients, those who experience only a few acute attacks in their lifetime, testing for urine ALA and PBG is most useful during an acute attack. Unless the patient has been treated with IV heme, testing for ALA and PBG can be done days after the acute attack. Studies of AIP patients showed that ALA and PBG can remain elevated for many months to years in urine after an acute attack (49). This is less so in HCP or VP, in which ALA and PBG levels can fall quickly after an acute attack. When testing is performed in sporatic AIP patients while they are asymptomatic, $44 \%$ to $15 \%$ can have normal urine ALA and PBG values $(50,51)$. The same is likely true for HCP and VP. In these patients, confirmatory testing may require repeat testing during an acute attack.

In the small population of AHP patients with recurrent acute attacks, ALA and PBG are typically elevated even at baseline, in between acute attacks (42). In patients who have frequent symptoms suggestive of acute attacks, normal ALA and PBG levels likely rule out AHP as the etiology of the symptoms.

Once the biochemical tests indicate AHP, confirmation of the specific type of AHP is usually established by genetic testing, with sequencing of the four genes $A L A D$, 
HMBS, CPOX and PPOX. When whole-gene sequencing is performed, $95-99 \%$ of cases can be identified (52). Once the proband mutation is defined, it is used to screen family members.

While mutation analysis is the gold standard for confirmation of diagnosis, it is not recommended for initial screening. This is due to the low penetrance of AHPs. Even in those with identification of a disease-causing mutation, confirmation of whether symptoms are due to acute attacks still requires biochemical testing.

Diagnosis of AHPs are frequently delayed, with the average time from onset of symptomatic AHP to diagnosis being 15 years in both the United States and Europe (37). Because of this, AHP should be considered in any women in their child-bearing years who presents with otherwise unexplained recurrent, severe abdominal pain.

\section{Differential diagnosis}

While the differential diagnosis for patients presenting with symptoms consistent with acute attacks is broad (36), a few specific diagnosis are worth more detailed discussion. Patients presenting with progressive weakness and neuropathy should be evaluated for Guillain-Barré syndrome (GBS). Some key differences include the lack of severe abdominal pain and autonomic nervous system involvement in GBS, and the lack of ascending paralysis in acute attacks (53). The most important difference is the presence in AHP of markedly elevated urine ALA and PBG, which are normal in GBS.

There are two conditions which can also present with elevated ALA levels and symptoms indistinguishable from acute attacks (54). In lead intoxication, excess lead inhibits the function of ALA dehydratase, the enzyme that is defective in ALAD porphyria (55). Biochemical testing shows isolated elevations of urine ALA but normal PBG, which helps distinguish it from AIP, VP and HCP attacks. Measuring the blood lead is definitive for diagnosis.

Hereditary tyrosinemia is an autosomal recessive disorder of tyrosine catabolism due to mutations in the fumarylacetoacetate hydrolase (FAH) gene. Patients with defective FAH function have abnormal accumulation of fumarylacetoacetate and succinyl acetone in hepatocytes which inhibit ALA dehydrase (56). Biochemical testing shows elevated ALA levels in the urine, but normal PBG. Clinically, hereditary tyrosinemia manifests in infancy or early childhood whereas AHP is rarely active before puberty $(57,58)$.

\section{Secondary coproporphyrinuria}

A common mistake in the diagnostic workup for AHPs is to screen for urine porphyrins, which do not include the porphyrin precursors ALA and PBG. Many patients without AHP show mild to moderate increases in urinary porphyrins, in particular coproporphyrins I and III. This is a nonspecific result that can be seen in a wide range of conditions unrelated to AHP $(59,60)$. The finding of isolated secondary coproporphyrinuria is rarely evidence of AHP.

\section{Treatment}

The mainstays of management during an acute attack are elimination of triggering factors, treatment of the acute symptoms, and therapy with intravenous heme.

\section{Identification of known triggers of acute attacks}

A number of conditions are known to induce heme synthesis and the expression of ALAS1 in the liver, which can lead to acute attacks. A mainstay in management of acute attacks is identifying and eliminating inducers of acute attacks.

Medications that are known to induce synthesis of cytochrome P450s are a well-known class of triggers for acute attacks. Several drug safety databases are available with lists of drugs (https://www.porphyriafoundation.com/drug-database; https://www.drugs-porphyria.org) that are considered risky as well as those that are thought to be safe (61).

Prolonged fasting also predisposes to acute attacks. First attacks of acute porphyria have been reported during a fast imposed by abdominal surgery or with extreme measures for weight loss such as a highly restricted diet or gastric bypass (62). Animal studies have shown that fasting induces the expression of peroxisome proliferator-activated receptor gamma coactivator 1-alpha (PGC-1 $\alpha$ ), which induces the expression of ALAS1 (63). This is the basis for giving carbohydrates to patients in an acute attack (64). Conversely, there is no evidence that a diet with excess carbohydrates protects against attacks. Instead, patients who take extra carbohydrates for this purpose can develop obesity. While exercise can affect caloric balance, it has never been implicated in acute attacks.

Changes in ovarian hormone levels are another possible inducer of attacks, with progestins likely more porphyrogenic than estrogens (65). In some cases, the attacks are recurrent and cyclic, occurring just prior to 
menstruation. Oral contraceptive use has been associated with acute attacks and is not recommended in AHP. Lowdose estrogen replacement therapy, on the other hand, appears to be safe (65). Pregnancy is usually uneventful, but acute attacks have been reported and may require treatment with intravenous heme (65).

\section{Treatment of acute attacks}

Carbohydrate infusions should be started early, with a goal of providing approximated $400 \mathrm{~g}$ of dextrose daily. While this has not been tested in a controlled trial, clinical experience indicates that it can result in symptomatic improvement in the early stages of attacks (66).

Hyponatremia can be seen in up to $30 \%$ of acute attacks. It may be due to hypovolemia secondary to prolonged nausea and vomiting or to the syndrome of inappropriate secretion of antidiuretic hormone (SIADH). This should be corrected carefully with saline administration, with precautions to minimize the risk of brainstem damage (67). Autonomic symptoms including tachycardia and hypertension are common and can be treated with propranolol (68).

Intravenous heme is the only currently approved therapy specific for acute attacks and should be started as soon as possible $(2,66,69-71)$. Heme rapidly down-regulates ALAS1 expression in the liver, thus stopping the continued accumulation of ALA and PBG. Symptomatic relief depends on elimination of excess ALA and PBG and typically takes 48-72 hours. Recovery rate of neurologic symptoms can vary, depending on the underlying pathology.

Heme can induce a chemical phlebitis when infused into small veins (72), thus It is given by slow drip into a large peripheral vein or central catheter. Reconstitution in albumin solution can reduce the risk of phlebitis (72). In Europe and most other countries, heme is complexed with the amino acid arginine to form heme arginate, which is stable in solution and marketed as Normosang (Orphan Europe SARL, Paris, France). Orally administered heme is degraded by intestinal heme oxygenase and is ineffective (70,73).

Complications from heme therapy is rare outside of phlebitis. Excessively high doses of heme can be nephrotoxic (74) and hepatotoxic (75). Rare anaphylaxis has been reported (76). With chronic administration, secondary iron overload is a common issue. These patients should be monitored with regular iron studies and treated with phlebotomy or iron chelator therapy when the ferritin is
$>1,000 \mathrm{ng}$ per $\mathrm{mL}$.

\section{Treatment of recurrent attacks:}

In recurrent attacks that appear linked to the menstrual cycle, ovulatory suppression with gonadotropin-releasing hormone $(\mathrm{GnRH})$ agonists may be helpful $(77,78)$. GnRH agonists are peptides that have no demonstrable porphyriainducing activity $(65,79)$. The main adverse effect is menopausal symptoms, which are not tolerated by some patients. Supplemental low-dose estrogen may be helpful for those whose porphyria symptoms are improving on treatment.

Patients who experience more than 3-4 attacks per year should consider prophylactic hematin therapy (80-82). Monitoring of ALA and PBG between attacks is helpful for optimizing the timing of prophylactic hematin therapy. Regular, long-term administration of hematin typically requires the placement of an indwelling venous catheter for access. Patients should be monitored for complications related to chronic hematin administration such as iron overload.

A novel therapy is in development for prevention of acute attacks based on RNA-interference against ALAS1. It uses small interfering RNA molecules that target the mRNA transcripts for ALAS1 specifically within hepatocytes to down-regulate excessive ALA production. Preclinical studies in a mouse model of AIP showed successful reduction of urine ALA levels without any evidence of oversuppression of heme synthesis (83). As of mid-2019, a phase I/II trial with open-label extension and a phase III trial are ongoing for attack prevention in patients experiencing at least 3 episodes annually. The data indicate a high degree of efficacy with acceptable side-effects $(40,42)$.

Patients with recurrent attacks often report symptoms between episodes, which vary from pain and mild nausea to chronic fatigue (84-86). Some live in constant fear of the next acute flare and want pain medication on hand, to take when they sense an attack building. Opioids are discouraged in this situation because of the very high risk of addiction. Other drugs for pain include gabapentin, tricyclic antidepressants, and acetaminophen. Some patients report benefit from marijuana, but others dislike the central side effects. Non-euphoriant preparations are under development that may expand the use of cannabinoids for pain control. Anti-emetics (ondansetron, promethazine and others) are often helpful and are safe in porphyria. Anxiolytics such as alprazolam, if used at all, 
should be started in very small doses. Muscle relaxants (benzodiazepines, carisoprodol) are avoided because of addiction potential. Also, carisoprodol has been linked to acute attacks. For patients taking opiates chronically, consultation with a pain management specialist is recommended.

\section{Liver transplantation}

In patients who have recurrent attacks and neurologic progression despite intensive hematin therapy, liver transplantation can be considered and is curative. To date 16 liver transplants have been reported $(87,88)$. Liver transplant rapidly normalizes ALA and PBG and resolves acute symptoms (87). Recovery of neurological function, however, has been variable, with long-standing deficits in some cases showing little or no improvement. Quadriplegia and respiratory paralysis are viewed as exclusionary for liver transplantation. Due to the morbidity and mortality associated with liver transplantation, it is considered as a treatment of last resort.

\section{Prognosis}

Prior to the development of heme therapy, AHP patients were at risk for increased mortality and severe neurological complications (89). With improved recognition of acute attacks, avoidance of known pharmacological triggers, better critical care and heme treatment, the prognosis of AHP has improved dramatically. Overall, patients can have a good prognosis, especially if their disease remains latent or when the diagnosis is made in a timely fashion, acute attacks are managed rapidly, and future attacks prevented.

Despite this, AHP patients remain at risk for significant morbidity. AHP patients with multiple recurrent attacks may develop chronic pain. The pathogenesis for this is unclear, but chronic neuropathy is likely part of the etiology $(16,90)$. These chronic symptoms may not respond to heme, and referral to a pain management specialist may be helpful for management of chronic neuropathic pain. AHP patients with persistent chronic pain symptoms can develop severe depression and anxiety, which is associated with an increased risk for suicide, and may require psychiatric monitoring and care (91).

AHP patients are at increased risk for chronic renal disease $(92,93)$. While systemic arterial hypertension usually resolves after resolution of an acute attack, some patients may develop chronic hypertension, which may be a cause of chronic renal damage. A common variant of peptide transporter 2 (PEPT2), a transporter for ALA in the kidney and brain, may predispose patients to develop chronic renal disease in AHP patients (94). Asymptomatic patients without elevated porphyrin precursors and porphyrins are not at risk of chronic renal disease (95). Due to the high prevalence of chronic kidney disease, serum creatinine and eGFR should be monitored annually for all symptomatic patients. Referral to a nephrologist is recommended if hypertension is not controlled by first line treatment or when renal dysfunction is first recognized.

AHP patients are also at higher risk for developing liver complications. A significant portion of AHP patients have increased serum transaminases during an acute attack 66 . Persistent elevations in serum transaminases are common in patients who have recurrent attacks. AHP patients may be at higher risk for developing cirrhosis than the general population. AHP patients, especially females, are at substantial risk for hepatocellular carcinoma $(96,97)$. The risk may be greatest in those with a history of active porphyria (recurrent attacks and/or chronically elevated ALA and PBG) or liver disease However, HCC can be seen in patients with no history of liver disease and no clinical findings suggestive of portal hypertension. A previous study suggested that AHP genes may act as tumor suppressor genes (98). In the tumors of two AHP patients who developed HCC, a second mutation in trans to the already mutated AHP gene was found. Liver function tests should be checked in all patients at baseline. An initial abdominal ultrasound and Fibroscan to screen for the presence of advanced liver disease should be performed. Patients found to have elevated liver enzymes or abnormal liver imaging should be evaluated for concomitant liver disease. Those with evidence of chronic liver injury should have cirrhosis and HCC screening starting at age 50 using abdominal imaging and serum alpha-fetoprotein (99).

\section{Acknowledgments}

The author would like to thank D. Montgomery Bissell for helpful discussions.

Funding: The author is supported by the following funding source: Porphyria Consortium (U54 DK083909).

\section{Footnote}

Provenance and Peer Review: This article was commissioned by the Guest Editors (Luca Fabris and Mario Strazzabosco) 
for the series "Recent Advances in Rare Liver Diseases" published in Translational Gastroenterology and Hepatology. The article was sent for external peer review organized by the Guest Editors and the editorial office.

Conflicts of Interest: The author has completed the ICMJE uniform disclosure form (available at http://dx.doi. org/10.21037/tgh-2020-01). The series "Recent Advances in Rare Liver Diseases" was commissioned by the editorial office without any funding or sponsorship. Dr. Wang reports personal fees from Recordati Rare Diseases, personal fees from Alnylam Pharmaceuticals, outside the submitted work. The author has no other conflicts of interest to declare.

Ethical Statement: The author is accountable for all aspects of the work in ensuring that questions related to the accuracy or integrity of any part of the work are appropriately investigated and resolved.

Open Access Statement: This is an Open Access article distributed in accordance with the Creative Commons Attribution-NonCommercial-NoDerivs 4.0 International License (CC BY-NC-ND 4.0), which permits the noncommercial replication and distribution of the article with the strict proviso that no changes or edits are made and the original work is properly cited (including links to both the formal publication through the relevant DOI and the license). See: https://creativecommons.org/licenses/by-nc-nd/4.0/.

\section{References}

1. Meissner P, Adams P, Kirsch R. Allosteric inhibition of human lymphoblast and purified porphobilinogen deaminase by protoporphyrinogen and coproporphyrinogen. A possible mechanism for the acute attack of variegate porphyria. J Clin Invest 1993;91:1436-44.

2. Bissell DM. Treatment of acute hepatic porphyria with hematin. J Hepatol 1988;6:1-7.

3. Sardh E, Rejkjaer L, Andersson DE, et al. Safety, pharmacokinetics and pharmocodynamics of recombinant human porphobilinogen deaminase in healthy subjects and asymptomatic carriers of the acute intermittent porphyria gene who have increased porphyrin precursor excretion. Clin Pharmacokinet 2007;46:335-49.

4. Soonawalla ZF, Orug T, Badminton MN, et al. Liver transplantation as a cure for acute intermittent porphyria. Lancet 2004;363:705-6.
5. Dowman JK, Gunson BK, Bramhall S, et al. Liver transplantation from donors with acute intermittent porphyria. Ann Intern Med 2011;154:571-2.

6. Brennan MJ, Cantrill RC. Delta-aminolaevulinic acid is a potent agonist for GABA autoreceptors. Nature 1979;280:514-5.

7. Muller WE, Snyder SH. delta-Aminolevulinic acid: influences on synaptic GABA receptor binding may explain CNS symptoms of porphyria. Ann Neurol 1977;2:340-2.

8. Puy H, Deybach JC, Bogdan A, et al. Increased delta aminolevulinic acid and decreased pineal melatonin production. A common event in acute porphyria studies in the rat. J Clin Invest 1996;97:104-10.

9. Di Mascio P, Teixeira PC, Onuki J, et al. DNA damage by 5-aminolevulinic and 4,5-dioxovaleric acids in the presence of ferritin. Arch Biochem Biophys 2000;373:368-74.

10. Douki T, Onuki J, Medeiros MH, et al. DNA alkylation by 4,5-dioxovaleric acid, the final oxidation product of 5-aminolevulinic acid. Chem Res Toxicol 1998;11:150-7.

11. Hermes-Lima M. How do Ca2+ and 5-aminolevulinic acid-derived oxyradicals promote injury to isolated mitochondria? Free Radic Biol Med 1995;19:381-90.

12. Costa CA, Trivelato GC, Pinto AM, et al. Correlation between plasma 5 -aminolevulinic acid concentrations and indicators of oxidative stress in lead-exposed workers. Clin Chem 1997;43:1196-202.

13. Carneiro RC, Reiter RJ. Melatonin protects against lipid peroxidation induced by delta-aminolevulinic acid in rat cerebellum, cortex and hippocampus. Neuroscience 1998;82:293-9.

14. Princ FG, Maxit AG, Cardalda C, et al. In vivo protection by melatonin against delta-aminolevulinic acid-induced oxidative damage and its antioxidant effect on the activity of haem enzymes. J Pineal Res 1998;24:1-8.

15. Karbownik M, Reiter RJ. Melatonin protects against oxidative stress caused by delta-aminolevulinic acid: implications for cancer reduction. Cancer Invest 2002;20:276-86.

16. Bonkowsky HL, Schady W. Neurologic manifestations of acute porphyria. Semin Liver Dis 1982;2:108-24.

17. Percy VA, Lamm MC, Taljaard JJ. delta-Aminolaevulinic acid uptake, toxicity, and effect on [14C]gammaaminobutyric acid uptake into neurons and glia in culture. J Neurochem 1981;36:69-76.

18. Cutler MG, Moore MR, Dick JM. Effects of deltaaminolaevulinic acid on contractile activity of rabbit duodenum. Eur J Pharmacol 1980;64:221-30.

19. Pierach CA, Edwards PS. Neurotoxicity of delta- 
aminolevulinic acid and porphobilinogen. Exp Neurol 1978;62:810-4.

20. Sylantiev C, Schoenfeld N, Mamet R, et al. Acute neuropathy mimicking porphyria induced by aminolevulinic acid during photodynamic therapy. Muscle Nerve 2005;31:390-3.

21. Doss M, von Tiepermann R, Schneider J, et al. New type of hepatic porphyria with porphobilinogen synthase defect and intermittent acute clinical manifestation. Klin Wochenschr 1979;57:1123-7.

22. Doss MO, Stauch T, Gross U, et al. The third case of Doss porphyria (delta-amino-levulinic acid dehydratase deficiency) in Germany. J Inherit Metab Dis 2004;27:529-36.

23. Thunell S, Holmberg L, Lundgren J. Aminolaevulinate dehydratase porphyria in infancy. A clinical and biochemical study. J Clin Chem Clin Biochem 1987;25:5-14.

24. Akagi R, Kato N, Inoue R, et al. delta-Aminolevulinate dehydratase (ALAD) porphyria: the first case in North America with two novel ALAD mutations. Mol Genet Metab 2006;87:329-36.

25. Nordmann Y, Puy H, Da Silva V, et al. Acute intermittent porphyria: prevalence of mutations in the porphobilinogen deaminase gene in blood donors in France. J Intern Med 1997;242:213-7.

26. Lenglet H, Schmitt C, Grange T, et al. From a dominant to an oligogenic model of inheritance with environmental modifiers in acute intermittent porphyria. Hum Mol Genet 2018;27:1164-73.

27. Chen B, Solis-Villa C, Hakenberg J, et al. Acute Intermittent Porphyria: Predicted Pathogenicity of HMBS Variants Indicates Extremely Low Penetrance of the Autosomal Dominant Disease. Hum Mutat 2016;37:1215-22.

28. Elder G, Harper P, Badminton M, et al. The incidence of inherited porphyrias in Europe. J Inherit Metab Dis 2013;36:849-57.

29. Hift RJ, Meissner PN. An analysis of 112 acute porphyric attacks in Cape Town, South Africa: Evidence that acute intermittent porphyria and variegate porphyria differ in susceptibility and severity. Medicine (Baltimore) 2005;84:48-60.

30. Dean G. The porphyrias : a story of inheritance and environment. London [etc.]: Pitman Medical; 1972.

31. Solis C, Martinez-Bermejo A, Naidich TP, et al. Acute intermittent porphyria: studies of the severe homozygous dominant disease provides insights into the neurologic attacks in acute porphyrias. Arch Neurol 2004;61:1764-70.

32. Hessels J, Voortman G, van der Wagen A, et al.

Homozygous acute intermittent porphyria in a 7-year-old boy with massive excretions of porphyrins and porphyrin precursors. J Inherit Metab Dis 2004;27:19-27.

33. Corrigall AV, Hift RJ, Davids LM, et al. Homozygous variegate porphyria in South Africa: genotypic analysis in two cases. Mol Genet Metab 2000;69:323-30.

34. Pinder VA, Holden ST, Deshpande C, et al. Homozygous variegate porphyria presenting with developmental and language delay in childhood. Clin Exp Dermatol 2013;38:737-40.

35. Schmitt C, Gouya L, Malonova E, et al. Mutations in human CPO gene predict clinical expression of either hepatic hereditary coproporphyria or erythropoietic harderoporphyria. Hum Mol Genet 2005;14:3089-98.

36. Anderson KE, Bloomer JR, Bonkovsky HL, et al. Recommendations for the diagnosis and treatment of the acute porphyrias. Ann Intern Med 2005;142:439-50.

37. Bonkovsky HL, Maddukuri VC, Yazici C, et al. Acute porphyrias in the USA: features of 108 subjects from Porphyrias Consortium. Am J Med 2014;127:1233-41.

38. Wikberg A, Andersson C, Lithner F. Signs of neuropathy in the lower legs and feet of patients with acute intermittent porphyria. J Intern Med 2000;248:27-32.

39. Patience DA, Blackwood DH, McColl KE, et al. Acute intermittent porphyria and mental illness--a family study. Acta Psychiatr Scand 1994;89:262-7.

40. Balwani M, Gouya L, Rees D, et al., editors. ENVISION, a phase 3 study to evaluate the efficacy and safety of Givosiran, an investigational RNAi therapeutic targeting aminolevulinic acid synthase 1 , in acute hepatic porphyria patients. EASL 54th Annual International Liver Congress; 2019; Vienna, Austria.

41. Ventura P, Gouya L, Balwani M, et al. Disease manifestations of patients with recurrent acute hepatic porphyria (AHP) and daily life impacts in EXPLORE international, prospective, natural history study. EASL 54th Annual International Liver Congress; 2019; Vienna, Austria 2019.

42. Sardh E, Harper P, Balwani M, et al. Phase 1 Trial of an RNA Interference Therapy for Acute Intermittent Porphyria. N Engl J Med 2019;380:549-58.

43. Floderus Y, Sardh E, Moller C, et al. Variations in porphobilinogen and 5 -aminolevulinic acid concentrations in plasma and urine from asymptomatic carriers of the acute intermittent porphyria gene with increased porphyrin precursor excretion. Clin Chem 2006;52:701-7. 
44. Wang B, Kapoor Y, Zenhari S, et al. Prevalence of chronic subacute symptoms in carriers of a mutation for autosomal dominant acute porphyria: a prospective, blinded study. International Congress on Porphyrins and Porphyrias; Bordeaux, France 2017.

45. Davis JR, Andelman SL. Urinary delta-aminolevulinic acid (ALA) levels in lead poisoning. I. A modified method for the rapid determination of urinary delta-aminolevulinic acid using disposable ion-exchange chromatography columns. Arch Environ Health 1967;15:53-9.

46. Zhang J, Yasuda M, Desnick RJ, et al. A LC-MS/MS method for the specific, sensitive, and simultaneous quantification of 5-aminolevulinic acid and porphobilinogen. J Chromatogr B Analyt Technol Biomed Life Sci 2011;879:2389-96.

47. Benton CM, Couchman L, Marsden JT, et al. Direct and simultaneous quantitation of 5-aminolaevulinic acid and porphobilinogen in human serum or plasma by hydrophilic interaction liquid chromatography-atmospheric pressure chemical ionization/tandem mass spectrometry. Biomed Chromatogr 2013;27:267-72.

48. Pierach CA, Cardinal R, Bossenmaier I, et al. Comparison of the Hoesch and the Watson-Schwartz tests for urinary porphobilinogen. Clin Chem 1977;23:1666-8.

49. Marsden JT, Rees DC. Urinary excretion of porphyrins, porphobilinogen and delta-aminolaevulinic acid following an attack of acute intermittent porphyria. J Clin Pathol 2014;67:60-5.

50. Andersson C, Thunell S, Floderus Y, et al. Diagnosis of acute intermittent porphyria in northern Sweden: an evaluation of mutation analysis and biochemical methods. J Intern Med 1995;237:301-8.

51. Kauppinen R, von und zu Fraunberg M. Molecular and biochemical studies of acute intermittent porphyria in 196 patients and their families. Clin Chem 2002;48:1891-900.

52. Whatley SD, Mason NG, Woolf JR, et al. Diagnostic strategies for autosomal dominant acute porphyrias: retrospective analysis of 467 unrelated patients referred for mutational analysis of the HMBS, CPOX, or PPOX gene. Clin Chem 2009;55:1406-14.

53. Albers JW, Fink JK. Porphyric neuropathy. Muscle Nerve 2004;30:410-22.

54. Bissell DM, Lai JC, Meister RK, et al. Role of deltaaminolevulinic acid in the symptoms of acute porphyria. Am J Med 2015;128:313-7.

55. Lubran MM. Lead toxicity and heme biosynthesis. Ann Clin Lab Sci 1980;10:402-13.

56. Gentz J, Johansson S, Lindblad B, et al. Exertion of delta- aminolevulinic acid in hereditary tyrosinemia. Clin Chim Acta 1969;23:257-63.

57. Badcock NR, O'Reilly DA, Zoanetti GD, et al. Childhood porphyrias: implications and treatments. Clin Chem 1993;39:1334-40.

58. Balwani M, Singh P, Seth A, et al. Acute Intermittent Porphyria in children: A case report and review of the literature. Mol Genet Metab 2016;119:295-9.

59. Doss MO. Porphyrinurias and occupational disease. Ann N Y Acad Sci 1987;514:204-18.

60. Gibson PR, Grant J, Cronin V, et al. Effect of hepatobiliary disease, chronic hepatitis $\mathrm{C}$ and hepatitis $\mathrm{B}$ virus infections and interferon-alpha on porphyrin profiles in plasma, urine and faeces. J Gastroenterol Hepatol 2000;15:192-201.

61. Hift RJ, Thunell S, Brun A. Drugs in porphyria: From observation to a modern algorithm-based system for the prediction of porphyrogenicity. Pharmacol Ther 2011;132:158-69.

62. Bonkovsky HL, Siao P, Roig Z, et al. Case records of the Massachusetts General Hospital. Case 20-2008. A 57-yearold woman with abdominal pain and weakness after gastric bypass surgery. N Engl J Med 2008;358:2813-25.

63. Handschin C, Lin J, Rhee J, et al. Nutritional regulation of hepatic heme biosynthesis and porphyria through PGC1alpha. Cell 2005;122:505-15.

64. Marver HS, Collins A, Tschudy DP, et al. Deltaaminolevulinic acid synthetase. II. Induction in rat liver. J Biol Chem 1966;241:4323-9.

65. Andersson C, Innala E, Backstrom T. Acute intermittent porphyria in women: clinical expression, use and experience of exogenous sex hormones. A population-based study in northern Sweden. J Intern Med 2003;254:176-83.

66. Stein JA, Tschudy DP. Acute intermittent porphyria. A clinical and biochemical study of 46 patients. Medicine (Baltimore) 1970;49:1-16.

67. Laureno R, Karp BI. Myelinolysis after correction of hyponatremia. Ann Intern Med 1997;126:57-62.

68. Beattie AD, Moore MR, Goldberg A, et al. Acute intermittent porphyria: response of tachycardia and hypertension to propranolol. Br Med J 1973;3:257-60.

69. Bonkowsky HL, Tschudy DP, Collins A, et al. Repression of the overproduction of porphyrin precursors in acute intermittent porphyria by intravenous infusions of hematin. Proc Natl Acad Sci U S A 1971;68:2725-9.

70. Lamon JM, Frykholm BC, Hess RA, et al. Hematin therapy for acute porphyria. Medicine (Baltimore) 1979;58:252-69.

71. Watson CJ, Pierach CA, Bossenmaier I, et al. Postulated 
deficiency of hepatic heme and repair by hematin infusions in the "inducible" hepatic porphyrias. Proc Natl Acad Sci U S A 1977;74:2118-20.

72. Anderson KE, Bonkovsky HL, Bloomer JR, et al. Reconstitution of hematin for intravenous infusion. Ann Intern Med 2006;144:537-8.

73. Raffin SB, Woo CH, Roost KT, et al. Intestinal absorption of hemoglobin iron-heme cleavage by mucosal heme oxygenase. J Clin Invest 1974;54:1344-52.

74. Dhar GJ, Bossenmaier I, Cardinal R, et al. Transitory renal failure following rapid administration of a relatively large amount of hematin in a patient with acute intermittent porphyria in clinical remission. Acta Med Scand 1978;203:437-43.

75. Frei P, Minder EI, Corti N, et al. Liver Transplantation because of Acute Liver Failure due to Heme Arginate Overdose in a Patient with Acute Intermittent Porphyria. Case Rep Gastroenterol 2012;6:190-6.

76. Daimon M, Susa S, Igarashi M, et al. Administration of heme arginate, but not hematin, caused anaphylactic shock. Am J Med 2001;110:240.

77. Anderson KE, Spitz IM, Bardin CW, et al. A gonadotropin releasing hormone analogue prevents cyclical attacks of porphyria. Arch Intern Med 1990;150:1469-74.

78. Herrick AL, McColl KE, Wallace AM, et al. LHRH analogue treatment for the prevention of premenstrual attacks of acute porphyria. Q J Med 1990;75:355-63.

79. Perlroth MG, Marver HS, Tschudy DP. Oral contraceptive agents and the management of acute intermittent porphyria. JAMA 1965;194:1037-42.

80. Lamon JM, Frykholm BC, Bennett M, et al. Prevention of acute porphyric attacks by intravenous haematin. Lancet 1978;2:492-4.

81. Schmitt C, Lenglet H, Yu A, et al. Recurrent attacks of acute hepatic porphyria: major role of the chronic inflammatory response in the liver. J Intern Med 2018;284:78-91.

82. Marsden JT, Guppy S, Stein P, et al. Audit of the Use of Regular Haem Arginate Infusions in Patients with Acute Porphyria to Prevent Recurrent Symptoms. JIMD Rep 2015;22:57-65.

83. Yasuda M, Gan L, Chen B, et al. RNAi-mediated silencing of hepatic Alas1 effectively prevents and treats the induced acute attacks in acute intermittent porphyria mice. Proc Natl Acad Sci U S A 2014;111:7777-82.

84. Millward LM, Kelly P, Deacon A, et al. Self-rated psychosocial consequences and quality of life in the acute porphyrias. J Inherit Metab Dis 2001;24:733-47.
85. Naik H, Stoecker M, Sanderson SC, et al. Experiences and concerns of patients with recurrent attacks of acute hepatic porphyria: A qualitative study. Mol Genet Metab 2016;119:278-83.

86. Simon A, Pompilus F, Querbes W, et al. Patient Perspective on Acute Intermittent Porphyria with Frequent Attacks: A Disease with Intermittent and Chronic Manifestations. Patient 2018;11:527-37.

87. Singal AK, Parker C, Bowden C, et al. Liver transplantation in the management of porphyria. Hepatology 2014;60:1082-9.

88. Yasuda M, Erwin AL, Liu LU, et al. Liver Transplantation for Acute Intermittent Porphyria: Biochemical and Pathologic Studies of the Explanted Liver. Mol Med 2015;21:487-95.

89. Ridley A. The neuropathy of acute intermittent porphyria. QJ Med 1969;38:307-33.

90. Wu CL, Ro LS, Jung SM, et al. Clinical presentation and electrophysiological findings of porphyric neuropathies: a follow-up study. Muscle Nerve 2015;51:363-9.

91. Jeans JB, Savik K, Gross CR, et al. Mortality in patients with acute intermittent porphyria requiring hospitalization: a United States case series. Am J Med Genet 1996;65:269-73.

92. Andersson C, Wikberg A, Stegmayr B, et al. Renal symptomatology in patients with acute intermittent porphyria. A population-based study. J Intern Med 2000;248:319-25.

93. Pallet N, Mami I, Schmitt C, et al. High prevalence of and potential mechanisms for chronic kidney disease in patients with acute intermittent porphyria. Kidney Int 2015;88:386-95.

94. Tchernitchko D, Tavernier Q, Lamoril J, et al. A Variant of Peptide Transporter 2 Predicts the Severity of Porphyria-Associated Kidney Disease. J Am Soc Nephrol 2017;28:1924-32.

95. Stewart MF. Review of hepatocellular cancer, hypertension and renal impairment as late complications of acute porphyria and recommendations for patient follow-up. J Clin Pathol 2012;65:976-80.

96. Sardh E, Wahlin S, Bjornstedt M, et al. High risk of primary liver cancer in a cohort of 179 patients with Acute Hepatic Porphyria. J Inherit Metab Dis 2013;36:1063-71.

97. Andant C, Puy H, Bogard C, et al. Hepatocellular carcinoma in patients with acute hepatic porphyria: frequency of occurrence and related factors. J Hepatol 2000;32:933-9.

98. Schneider-Yin X, van Tuyll van Serooskerken 
AM, Siegesmund $M$, et al. Biallelic inactivation of protoporphyrinogen oxidase and hydroxymethylbilane synthase is associated with liver cancer in acute porphyrias. J Hepatol 2015;62:734-8.

doi: 10.21037/tgh-2020-01

Cite this article as: Wang B. The acute hepatic porphyrias. Transl Gastroenterol Hepatol 2021;6:24.
99. Balwani M, Wang B, Anderson KE, et al. Acute hepatic porphyrias: Recommendations for evaluation and longterm management. Hepatology 2017;66:1314-22. 